confirmed by pregnancy after infusion of porcine LH-RH. $₹$ Clin Endocrinol Metab $1971 ; 33: 980-2$.

${ }^{7}$ Nillius SJ. Gonadotrophin-releasing hormone for induction of ovulation in women. In: Hafez ESE, ed. Human ovulation. Amsterdam: North Holland, 1979:385-404.

" Mortimer CH, Besser GM, McNeilly AS. Uses. In: Motta M, Crosignani PG, Martini L, eds. Hypothalamic hormones, chemistry, physiology, pharmacology and clinical uses. New York: Academic Press, 1975:325-35.

${ }^{9}$ Leyendecker G, Wildt L, Hansmann M. Pregnancies following chronic intermittent (pulsatile) administration of $\mathrm{Gn}-\mathrm{RH}$ by means of a portable pump ("Zyklomat")-a new approach to the treatment of infertility in hypothalamic amenorrhoea. 7 Clin Endocrinol Metab 1980;51:1214-6.

10 Shoemaker J, Simons AHM, van Osnabrugge GJC, Lugtenburg C, van Kessel $\mathrm{H}$. Pregnancy after prolonged pulsatile administration of LHRH in a patient with clomiphene resistant secondary amenorrhoea. $\mathcal{F}$ Clin Endocrinol Metab $1981 ; 52: 882-5$.

"Crowley WF Jr, McArthur JW. Simulation of the normal menstrual cycle in Kallman's syndrome by pulsatile administration of luteinizing hormone-releasing hormone. $\mathcal{F}$ Clin Endocrinol Metab 1980;51:173-5.

12 Reid RL, Leopold GR, Yen SSC. Induction of ovulation and pregnancy with pulsatile luteinizing hormone releasing factor: dosage and mode of delivery. Fertil Steril $1981 ; 36: 553-9$.

${ }^{13}$ Leyendecker G, Struve T, Plotz EJ. Induction of ovulation with chronic intermittent (pulsatile) administration of LH-RH in women with hypothalamic and hyperprolactinemic amenorrhea. Arch Gynecol 1980;229: 177-90.

${ }^{14}$ Leyendecker G, Wildt L, Hansmann M. Pregnancies following chronic intermittent (pulsatile) administration of $\mathrm{Gn}-\mathrm{RH}$ by means of a portable pump-a new approach to treatment of infertility in hypothalamic amenorrhoea. F Clin Endocrinol Metab 1980;51:1214-26.

15 Skarin G, Nillius SJ, Wide L. Pulsatile low dose LHRH treatment for induction of follicular maturation and ovulation in women with amenorrhoea. Acta Endocrinol 1982;101:78-86.

${ }^{16}$ Keogh EJ, Mallal SA, Giles PFH, Evans DV. Ovulation induction with intermittent subcutaneous LHRH. Lancet 1981 ; : 147.
17 Hull MGR, Knuth UA, Murray MAF, Jacobs HS. The practical value of the progestogen challenge test, serum oestradiol estimation or clinical examination in assessment of the oestrogen state and response to clomiphene in amenorrhoea. Br F Obstet Gynaecol 1979;86:799-805.

${ }^{18}$ Kallmann FJ, Schonfeld WA, Barrera SE. Genetic aspects of primary eunuchoidism. Am 7 Ment Defic 1944;48:203-36.

19 Knuth UA, Hull MGR, Jacobs HS. Amenorrhoea and loss of weight. $B r \mathcal{F}$ Obstet Gynaecol 1977;84:801-7.

20 Yen SSC, Tsai CC, Naftolin F, van den Berg G, Ajabor L. Pulsatile patterns of gonadotrophin release in subjects with and without ovarian function. $\mathcal{f}$ Clin Endocrinol Metab 1972;34:671-5.

21 Backstrom CT, McNeilly AS, Leask RM, Baird DT. Pulsatile secretion of $\mathrm{LH}, \mathrm{FSH}$, prolactin, oestradiol and progesterone during the human menstrual cycle. Clin Endocrinol 1982;17:29-37.

22 Rothwell D, Sutherland IA, Pickup JC. A new miniature, open-loop, extracorporeal insulin infusion pump. 7 Biomed Eng 1983;5:177-272.

23 Toone BK, Wheeler M, Fenwick PBC. Sex hormone changes in male epileptics. Clin Endocrinol 1980;12:391-5.

24 Tucker M, Mason WP, Adams J, Jacobs HS. Multicystic enlarged ovaries -a new syndrome? In: Royal College of Obstetricians and Gynaecologists, ed. Programme of 23rd British congress of obstetricians and gynaecologists. Birmingham: Royal College of Obstetricians and Gynaecologists, 1983:1143.

${ }^{25} \mathrm{Knobil} \mathrm{E}$. The neuroendocrine control of the menstrual cycle. Recent Prog Horm Res 1980;36:53-88.

${ }^{26}$ Smith MA, Perrin MH, Vale WW. Desensitization of cultured pituitary cells to gonadotropin-releasing hormone: Evidence for a post-receptor mechanism. Mol Cell Endocrinol 1983;30:85-96.

27 Gemzell CA. Induction of ovulation with human gonadotrophins. $\mathcal{f}$ Reprod Med 1977;18:155-8.

${ }^{28}$ Bogchelman D, Lappöhn RE, Janssens J. Triplet pregnancy after pulsatile administration of gonadotrophin releasing hormone. Lancet $1982 ; \mathrm{ii}: 45-6$.

(Accepted 24 November 1983)

\title{
Role of exercise testing early after myocardial infarction in identifying candidates for coronary surgery
}

\author{
K JENNINGS，D S REID，T HAWKINS，D J JULIAN
}

\begin{abstract}
It has been suggested that ST depression in lead V5 or equivalent on early exercise testing after acute myocardial infarction predicts a high risk of death. To evaluate exercise testing and radionuclide ventriculography in this context 103 consecutive patients with myocardial infarction who were able to undertake a limited exercise test before discharge from hospital were exercised and underwent gated blood pool scanning. No serious complications resulted from exercise testing. Twenty nine patients developed ST depression in lead V5, 19 had exertional hypotension, 31 developed a heart rate of $\geqslant 130$ beats/min, and 15 had complex ventricular arrhythmias. Death during the first year after discharge from hospital was associated with exertional hypotension $(p<0.001)$ and a heart rate on exercise testing of $\geqslant 130$ beats $/$ min $(p<0.05)$; these two variables identified all nine deaths. Inability to complete the exercise protocol for any reason was also predictive of death $(\mathbf{p}<0.01)$.
\end{abstract}

Cardiology Department, Freeman Hospital, Newcastle upon Tyne NE7 7DN

K JENNINGS, MB, MRCP, senior registrar

D S REID, MB, FRCP, consultant cardiologist

D G JULIAN, MD, FRCP, professor of cardiology

Regional Medical Physics Department, Freeman Hospital

T HAWKINS, BSC, senior physicist

Correspondence to: Dr K Jennings, Royal Infirmary, Aberdeen AB9 2ZB.
Ventricular arrhythmias and ST depression in lead V5 induced by exercise were not significantly associated with an increased risk of death. The mean (SD) radionuclide ejection fraction in the patients who died was 29 (16)\% compared with 43 (11)\% in the patients who survived $(\mathbf{p}<\mathbf{0 . 0 0 1})$.

ST changes on exercise testing after myocardial infarction appear to be less predictive of later complications than haemodynamic signs, which may indicate left ventricular damage rather than ischaemia.

\section{Introduction}

The high mortality among patients in the months after myocardial infarction and the existence of treatments that may prove beneficial to some survivors but harmful to others make it necessary to identify the variables that characterise patients likely to benefit from specific forms of treatment. It has been suggested that exercise testing early after infarction may identify such variables; one study showed that ST depression in lead CM5 induced by exercise early after infarction predicted death in the following year. ${ }^{1}$ Akhras et al suggested that this ST change might be an indication for early coronary surgery because it represents hazardous but reversible ischaemia. ${ }^{2}$ If such findings were confirmed exercise testing after infarction might prove valuable in identifying patients who would benefit from early revascularisation. To evaluate the exercise test in this context we reviewed a consecutive population of patients who were able to undertake a limited exercise protocol early after infarction. 


\section{Patients and methods}

\section{STUDY POPULATION}

Over a period of 12 months 1253 patients were admitted to the coronary care unit at this hospital. Subsequently, 503 were found to have sustained myocardial infarction. Altogether 289 of the 503 patients were aged less than 66 and had at least two of the following three criteria for myocardial infarction: ischaemic pain lasting for at least 30 minutes; new $\mathrm{Q}$ waves or evolutionary ST-T wave changes; and a rise in creatine kinase activity to at least twice the upper limit of normal. Fifty one $(18 \%)$ of the 289 patients died in hospital and $86(36 \%)$ of the survivors were excluded from exercise testing because of continuing ischaemic pain, cardiac failure, left bundle branch block, complex arrhythmias, severe non-cardiac disease, or unwillingness to perform an exercise test. A further 49 patients were not exercised at this time because the test could not be arranged before their discharge. Thus we studied 103 patients with definite myocardial infarction who could be exercised before discharge. Their mean age was 54 (range 35-65), and 13 were women. Fifty three patients had had anterior infarction, 46 inferior infarction, and four true posterior infarction. Every survivor was followed up for at least one year.

Of the 103 patients, six were taking part in a randomised study of medical and surgical treatment and were randomly selected for surgery; all six were alive and well at least one year later. Because surgery was likely to have interfered with the natural course of their disease, however, we excluded them from one year analysis. We therefore present the results of follow up in 97 patients.

\section{TREADMILL EXERCISE TEST}

The table shows the exercise protocol. It required patients to exercise to a low degree of work up to a maximum of 5 mets (multiples of resting energy expenditure), which is roughly the magnitude of work we expect patients after infarction to be able to undertake at home soon after discharge from hospital. These exercise tests were performed on a motorised treadmill five to 30 (mean 12) days after infarction. The exercise was stopped if the patient developed severe symptoms that prevented continuation, a sustained heart rate of $\geqslant 130$ beats/min, a fall in systolic blood pressure, or more than three consecutive ventricular extrasystoles.

Exercise protocol for early after myocardial infarction

\begin{tabular}{cccc}
\hline $\begin{array}{c}\text { Speed } \\
(\mathrm{mph})\end{array}$ & $\begin{array}{c}\text { Incline } \\
(\%)\end{array}$ & $\begin{array}{c}\text { Workload } \\
\left(\text { mets }^{*}\right)\end{array}$ & $\begin{array}{c}\text { Cumulative } \\
\text { time } \\
\text { (minutes) }\end{array}$ \\
\hline 2 & 0 & 2 & 2 \\
2 & 3.5 & 3 & 4 \\
2 & 7.0 & 4 & 6 \\
2 & 10.5 & 5 & 8
\end{tabular}

${ }^{*}$ Mets $=$ Multiples of resting energy expenditure.

\section{DEFINITIONS}

An ischaemic response was defined as exercise induced ST depression $\geqslant 1 \mathrm{~mm} 0.08 \mathrm{~s}$ from the $\mathrm{J}$ point of the $Q R S$ complex, with or without angina. Exertional hypotension was defined as a fall in systolic pressure of $\geqslant 10 \mathrm{~mm} \mathrm{Hg}$ from the resting pressure or $\geqslant 20 \mathrm{~mm} \mathrm{Hg}$ from a pressure previously recorded during exercise after a rise from the resting pressure.

Patients who developed more than five ventricular extrasystoles/ minute, multiform extrasystoles, or ventricular tachycardia were said to have complex ventricular arrhythmias. Patients with a heart rate of $\geqslant 130$ beats/min were said to have an inappropriate heart rate response. ${ }^{3}$ Ten patients were receiving propranolol and four digoxin at the time of exercise testing.

\section{RADIONUCLIDE VENTRICULOGRAPHY}

To assess left ventricular function noninvasively, in vivo labelling of the blood pool was performed with pyrophosphate and $550 \mathrm{MBq}$ $(15 \mathrm{mCi}){ }^{99 \mathrm{~m}} \mathrm{Tc}$. Studies were performed within one month after infarction. Patients were imaged with a gammacamera (Technicare Sigma 410) with a large field of view, and data processing was carried out with a link system (Dyanne) computer. Studies of 10 minutes' duration were performed routinely in the optimal left anterior oblique projection. Each study consisted of 20 to 22 frames of data with typically 120000 counts/image. The ejection fraction was calculated using manually defined regions of interest at end diastole and end systole with a fixed background region of interest selected on the end diastolic frame. The ejection fraction was determined from the background corrected end diastolic and end systolic counts.

\section{CLINICAL VARIABLES}

The Norris index was calculated for every patient to determine whether clinical indices of prognosis could identify patients with poor prognosis more successfully than exercise variables. ${ }^{4}$ This index relates risk after myocardial infarction to four variables-namely, age, previous infarction, cardiac size, and pulmonary congestionwith a system of weighted scores. Mortality over the three years after infarction was reported as $12 \%$ in patients with an index of less than three, increasing to $85 \%$ for those with an index of 12 or more.

\section{STATISTICS}

We used the $\chi^{2}$ and Student's $t$ tests when appropriate for statistical analysis.

\section{Results}

Follow up was available to one year in all surviving patients. Fourteen patients sustained serious late complications within one year of infarction: nine died, three had non-fatal reinfarction, and two developed pulmonary oedema after discharge. Thus one year mortality in this group of patients was $8.7 \%$. Mortality in the 49 patients for whom exercise could not be arranged before discharge was similar at $8.2 \%$, implying that there was no difference between the two groups. Mortality in the 86 patients excluded from exercise because of complications of infarction was higher $(20.9 \%)$, as might be expected.

\section{EXERCISE TESTING}

Twenty nine patients developed exercise induced ST depression of $\geqslant 1 \mathrm{~mm}$ in lead V5 and 68 did not. Three patients $(10 \%)$ with ST depression in lead V5 died in the year after acute infarction compared with six $(9 \%)$ of the 68 patients without. This was not a significant difference. We also looked at the ability of ST depression in lead V5 to predict pulmonary oedema and non-fatal reinfarction in addition to death. One $(3 \%)$ of the 29 patients with ST depression in lead V5 had these complications compared with four $(6 \%)$ of the 68 patients without. These proportions were not significantly different. Twenty patients had $\geqslant 2 \mathrm{~mm}$ ST depression in lead V5, but this magnitude of ST shift did not identify patients with increased risk of early death. Furthermore, a total of 47 patients had $\geqslant 1 \mathrm{~mm}$ ST depression in any lead, including V5. This also did not predict increased mortality.

Nineteen patients developed exertional hypotension. Six $(32 \%)$ of these 19 patients died compared with only three $(4 \%)$ of the 78 patients with normal blood pressure on exercise $(p<0.001)$. In addition, one $(5 \%)$ of the 19 patients whose blood pressure fell had serious late complications compared with four $(5 \%)$ of those with normal blood pressure responses. Thirty one patients developed a heart rate of $\geqslant 130$ beats/min during exercise. Six of these patients $(19 \%)$ died compared with only three $(5 \%)$ of the 66 patients with a normal rate response to exercise $(p<0 \cdot 05)$. These nine deaths all occurred in the 44 patients with abnormal exercising haemodynamic responses-that is, a fall in systolic pressure or an inappropriate heart rate $(p<0.01)$. Two $(5 \%)$ of the 44 patients with abnormal haemodynamic responses developed serious late complications compared with three $(6 \%)$ of the 53 patients who had a normal blood pressure and heart rate on exercise. Of these 53 patients, none died.

Fifteen patients showed exercise induced ventricular arrhythmias and 82 patients did not. Two $(13 \%)$ of the patients with arrhythmias died compared with seven $(9 \%)$ of the 82 patients without. This was not a significant difference.

Fifty patients were unable to complete the limited exercise protoco for one or more reasons. Eight $(16 \%)$ of these patients died compared with only one $(2 \%)$ of the 47 patients who completed the protoco 
$(\mathrm{p}<0.05)$. Two $(4 \%)$ of the 50 patients unable to complete the test developed serious late complications, as did three $(6 \%)$ of the 47 patients who completed the test.

Exercise testing induced angina in 19 patients. Fourteen (74\%) of these 19 patients developed angina at follow up compared with $25(32 \%)$ of the 78 patients who did not have angina on exercise testing soon after infarction $(p<0.01)$. Exercise testing elicited normal responses in only 15 patients (four of whom developed test angina); none of these 15 sustained a serious complication during follow up. The four patients with angina on exercise testing developed severe limiting angina at follow up.

Forty two patients took beta blockers at some time during the year of follow up; 19 of these had had ST depression in lead V5 induced by exercise. This was elective treatment for the control of symptoms as it was not our policy to treat these patients routinely with beta blockade. Ten patients were exercised while taking beta blockers; three of them developed exertional hypotension. Four patients were exercised while taking digoxin, of whom three developed hypotension induced by exercise. (One of these patients was taking both digoxin and beta blockers.)

\section{RADIONUCLIDE VENTRICULOGRAPHY}

Ninety one of the 97 patients underwent gated blood pool scanning within a month of infarction. The mean (SD) ejection fraction in the six patients who underwent scanning and subsequently died was $29(16) \%$. This compared with a mean ejection fraction of $43(11) \%$ in the 85 patients who survived $(p<0.001)$. Five of the six patients who died had ejection fractions of less than $40 \%$ compared with only 29 of the 85 survivors.

\section{NORRIS CORONARY PROGNOSTIC INDEX}

The mean (SD) index in the group of patients who died was $5 \cdot 1$ (3.3) compared with $3.6(2 \cdot 5)$ in the survivors. This difference was not significant. Only two of the nine patients who died had coronary prognostic indexes of more than five (seven and 13). The patients at increased risk after infarction in this series would not therefore have been correctly identified with this prognostic index.

\section{Discussion}

Exercise testing early after infarction appears to identify a group of patients who will experience serious complications in the following year. We found that patients who were unable to achieve a normal blood pressure response or who developed an inappropriately increased heart rate to a low degree of exercise were at increased risk. These abnormal haemodynamic responses to exercise suggest extensive myocardial damage in this group of patients. It has been suggested that an inappropriate tachycardia ${ }^{3}$ or exertional hypotension ${ }^{5}$ at reduced workloads reflects reduced left ventricular function and a greater infarct size. ${ }^{6}$ In addition, we found that patients unable to complete the limited protocol had an increased risk of death, and this variable has been shown to be strongly associated with left ventricular failure. ${ }^{78}$ Support for this was provided in our study by the results of radionuclide ventriculography, the ejection fraction being significantly depressed in those patients who died compared with those who survived.

Not all patients who died, however, had a low ejection fraction, and possibly in these patients death was associated with severe coronary disease and ischaemia rather than pump failure or possibly these responses were associated with autonomic deconditioning. Patients with abnormal exercising haemodynamic responses should therefore undergo radionuclide ventriculography to establish the severity of any ventricular dysfunction.

We did not find that ST depression in lead V5 induced by exercise was significantly associated with death. This is in contrast to some reports ${ }^{910}$ but not to others. ${ }^{611-13}$ The most likely explanation for this disparity is the difference in patient selection between the studies in terms of age, extent of left ventricular dysfunction, and exercise protocols used.
As expected, we found that angina during the early exercise test is strongly associated with angina after discharge. Like Weld $e t a l^{7}$ we found that angina induced by exercise did not independently predict high mortality, although this association has been reported. ${ }^{10}$ We found that a normal response to exercise testing soon after infarction, or a normal response apart from symptoms of angina, identified a group of patients who would have an uncomplicated follow up, or follow up complicated only by angina.

The patients exercised in this study might have been expected to have a good prognosis as we had excluded patients with angina, cardiac failure, or complex arrhythmias continuing after infarction. These exclusions may explain why the coronary prognostic index was unhelpful in identifying increased risk. None of these patients experienced any serious or lasting complications of exercise testing, but deaths either during or soon after exercise testing after infarction have been reported by others, albeit rarely (D A Chamberlain, personal communication). ${ }^{14}$ These patients are at increased risk of sudden death whether they are exercising or not, and it is not clear whether these deaths were directly attributable to the exercise test. The risk associated with exercise testing after infarction appears to be small, particularly in relation to the valuable prognostic information it provides and the psychotherapeutic effects on most patients, who are encouraged by their exercise tolerance soon after myocardial infarction.

In our experience ST changes on exercise testing after infarction are less predictive of later complications than haemodynamic observations, which may indicate left ventricular damage rather than ischaemia. Our findings suggest, however, that patients with reduced exercise tolerance or poor haemodynamic responses are at particularly high risk of further ischaemic damage from infarction, which coronary artery surgery might prevent.

\section{References}

1 Theroux P, Waters DD, Halphen C, Debasieux J-C, Mizgala HF Prognostic value of exercise testing soon after myocardial infarction. $N$ Engl f Med 1979;301:341-5.

${ }^{2}$ Akhras F, Upward J, Stott R, Jackson G. Early exercise testing and coronary angiography after uncomplicated myocardial infarction. Br Med F 1982;284:1293-4.

${ }^{3}$ Granath A, Sodermark T, Winge T, Volpe U, Zetterquist S. Early work load tests for evaluation of long-term prognosis of acute myocardial infarction. Br Heart 7 1977;39:758-63.

4 Norris RM, Caughey DE, Mercer CJ, Deeming LW, Scott PJ. Coronary prognostic index for predicting survival after recovery from acute myocardial infarction. Lancet 1970 ;ii:485-8.

5 Kentala E, Pyorala K, Heikkila J, Sarna S, Luurila O. Factors related to long-term prognosis following acute myocardial infarction: importance of left ventricular function. Scand F Rehabil Med 1975;7:118-24.

${ }^{6}$ Grande P, Pederson A. Myocardial infarct size and cardiac performance at exercise soon after myocardial infarction. Br Heart 7 1982;47:44-50.

${ }^{7}$ Weld FM, Chu K-L, Bigger JT Jr, Rolnitzky LM. Risk stratification with low-level exercise testing 2 weeks after acute myocardial infarction. Circulation 1981;64:306-14.

8 Paine TD, Dye LE, Roitman DI, et al. Relation of graded exercise test findings after myocardial infarction to extent of coronary artery disease and left ventricular function. Am $\mathcal{F}$ Cardiol 1978;42:716-23.

${ }^{9}$ Sami M, Kraemer H, DeBusk RF. The prognostic significance of serial exercise testing after myocardial infarction. Circulation $1979 ; 60: 1238-46$

10 Starling MR, Crawford MH, Kennedy GT, O'Rourke RA. Exercise testing early after myocardial infarction: predictive value for subsequent unstable angina and death. Am f Cardiol 1980;46:909-14.

11 Borer JS, Rosing DR, Miller RH, et al. Natural history of left ventricular function during 1 year after acute myocardial infarction: comparison with clinical, electrocardiographic and biochemical determinations. Am 7 Cardiol 1980;46:1-12.

12 Corbett JR, Dehmer GJ, Lewis SE, et al. The prognostic value of submaximal exercise testing with radionuclide ventriculography before hospital discharge in patients with recent myocardial infarction. Circulation 1981;64:535-44.

13 Jelinek VM, McDonald IG, Ryan WF, Ziffer RW, Clemens A, Gerloff J. Assessment of cardiac risk 10 days after uncomplicated myocardial infarction. Br Med $\mathcal{F} 1982 ; 284: 227-33$.

14 Pedersen A, Grande P, Saunamäki K, Schaadt O. Exercise testing after myocardial infarction. $N$ Engl F Med 1980;302:174.

(Accepted 25 October 1983) 